\title{
Profile of Nepalese optometrists and their perspectives about a new optometry school
}

\begin{tabular}{|c|c|}
\hline $\begin{array}{l}\text { Authors: } \\
\text { Dinesh Kaphle } \\
\text { Himal Kandel } \\
\text { Hrakash Paudel } \\
\text { Provin Naidoo } \\
\text { Ko }\end{array}$ & $\begin{array}{l}1,2 \text { (1) } \\
\text { (1) } \\
\left.\right|^{4} \text { (1) } \\
50\end{array}$ \\
\hline 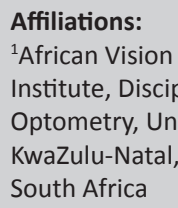 & $\begin{array}{l}\text { Research } \\
\text { pline of } \\
\text { iversity of } \\
\text { Durban, }\end{array}$ \\
\hline $\begin{array}{l}{ }^{2} \text { School of Optc } \\
\text { Vision Science, } \\
\text { University of Te, } \\
\text { Brisbane, Austr }\end{array}$ & $\begin{array}{l}\text { ometry and } \\
\text { Queensland } \\
\text { echnology, } \\
\text { ralia }\end{array}$ \\
\hline $\begin{array}{l}{ }^{3} \text { Save Sight Inst } \\
\text { Sydney Medica } \\
\text { The University } \\
\text { Sydney, Austra }\end{array}$ & $\begin{array}{l}\text { titute, } \\
\text { l School, } \\
\text { of Sydney, } \\
\text { lia }\end{array}$ \\
\hline $\begin{array}{l}{ }^{4} \text { BKP Lions Cen } \\
\text { Ophthalmic Stu } \\
\text { of Medicine, Ka } \\
\text { Nepal }\end{array}$ & $\begin{array}{l}\text { tre for } \\
\text { udies, Institute } \\
\text { athmandu, }\end{array}$ \\
\hline $\begin{array}{l}\text { 5School of Optc } \\
\text { Vision Science, } \\
\text { New South Wa } \\
\text { Australia }\end{array}$ & $\begin{array}{l}\text { ometry and } \\
\text { University of } \\
\text { les, Sydney, }\end{array}$ \\
\hline $\begin{array}{l}\text { Corresponding } \\
\text { Dinesh Kaphle, } \\
\text { dinesh.kaphle }\end{array}$ & $\begin{array}{l}\text { author: } \\
\text { @gmail.com }\end{array}$ \\
\hline $\begin{array}{l}\text { Dates: } \\
\text { Received: } 25 \mathrm{~S} \\
\text { Accepted: } 02 \mathrm{~A} \\
\text { Published: } 30 \mathrm{C}\end{array}$ & $\begin{array}{l}\text { ept. } 2018 \\
\text { Aug. } 2019 \\
\text { Oct. } 2019\end{array}$ \\
\hline $\begin{array}{l}\text { How to cite thi } \\
\text { Kaphle D, Kand } \\
\text { Naidoo K. Profi } \\
\text { optometrists a } \\
\text { perspectives ah } \\
\text { optometry sch } \\
\text { Eye Health. } 20 \\
\text { https://doi.org } \\
\text { aveh.v78i1.476 }\end{array}$ & $\begin{array}{l}\text { is article: } \\
\text { del } \mathrm{H} \text {, Paudel } \mathrm{P}, \\
\text { ile of Nepalese } \\
\text { nd their } \\
\text { bout a new } \\
\text { ool. Afr Vision } \\
19 ; 78(1) \text {, a } 476 . \\
/ 10.4102 / \\
5\end{array}$ \\
\hline Read online: & \\
\hline 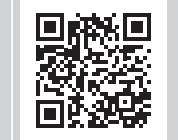 & $\begin{array}{l}\text { Scan this QR } \\
\text { code with your } \\
\text { smart phone or } \\
\text { mobile device } \\
\text { to read online. }\end{array}$ \\
\hline
\end{tabular}

Background: The optometry training programme started in Nepal in 1997 with an intake of six students per year. The second optometry school was established in 2018 with an intake of 40 students per year.

Aim: To establish a profile for Nepalese optometrists and understand their perspectives regarding the entrance examination, curriculum, infrastructure and recruitment of lecturers for a newly opened second optometry school.

Setting: The prospective study respondents were contacted by email and the survey was administered online.

Methods: A semi-structured questionnaire was emailed to 118 registered optometrists of the Nepalese Association of Optometrists, and the response rate of the survey was 69\%. The questionnaire contained broad areas such as demographics of participants, their scope of practice, mode of entrance examination and content of the course curriculum, and availability of adequate infrastructure and lecturers.

Results: A vast majority (93\%) of the respondents suggested that optometrists should have been involved more in the planning of the programme. Over half of the respondents (57.5\%) suggested that the programme should go ahead with a revised curriculum and wellequipped laboratories. The qualitative analysis produced four broad themes: (1) quality assurance and control; (2) resources; (3) curriculum development and implementation; and (4) professional standards and opportunities. The responders expressed several strategies to address these concerns, including communicating with stakeholders and filing a case in the court for starting up a new optometry school without sufficient involvement of the existing optometrists.

Conclusion: The recommendations for improvement include conducting impartial entrance examinations, establishing equipped laboratories and recruiting adequate lecturers.

Keywords: perspectives; optometry school; Nepal; cross-sectional survey; optometrists.

\section{Introduction}

The VISION 2020: The Right to Sight, a global initiative for the elimination of avoidable blindness by the year 2020, recommends one refractionist or optometrist per every 50000 population. ${ }^{1}$ To meet this guideline for Nepal, there should be approximately 700 optometrists for the current population of nearly 30 million. ${ }^{2}$ Until 2017, Institute of Medicine (IOM), Tribhuvan University, was the only institution providing optometry education in Nepal. The IOM started the Bachelor of Optometry (BOptom) programme in 1997 with six optometrists graduating per year, and recently, the number increased to 10 optometrists per year. ${ }^{3}$ It would take many decades to produce the required target for VISION 2020 from a single university at the current rate. However, it is also a challenge to retain the optometrists in the country; nearly $50 \%$ of the IOM graduates have migrated abroad for further study or better opportunities. $^{4}$

Eye care services in Nepal are provided by eye hospitals affiliated to non governmental organisations, largely by the Nepal Netra Jyoti Sangh (NNJS) and Tilganga Institute of Ophthalmology. ${ }^{5}$ Most eye hospitals are run by the ophthalmologists and ophthalmic assistants

Copyright: ( 2019. The Author(s). Licensee: AOSIS. This work is licensed under the Creative Commons Attribution License. 
(OAs), and provide cataract surgeries and ocular diseases treatment, but have very few optometrists. Ophthalmic assistants, paramedical eye professionals with a diploma in ophthalmic science qualification, are being trained by the NNJS and the Tilganga Institute of Ophthalmology at different eye hospitals in Nepal. Although the OAs are primarily trained to assist ophthalmologists for eye surgeries and treating ocular pathologies, they also provide ophthalmic services including refractions in many rural parts of Nepal. ${ }^{5}$ However, OAs do not provide any specialised optometry services such as low vision, contact lenses and vision therapies. ${ }^{5}$ Furthermore, given the recent emergence and growth in advanced procedures including myopia control strategies, ${ }^{6}$ these OAs will also face deficits in the management of refractive conditions.

The National Academy of Medical Science (NAMS) introduced a Bachelor of Optometry and Vision Science course in January 2018, which is the second optometry programme in the country. Existing optometrists were not directly involved in the initiation of the programme, although two optometrists participated in the curriculum development workshop through informal communication. One of the arguments that the NAMS has put forward for opening the new school is to increase the number of optometrists working in Nepal. The new programme plans to produce 40 optometrists (two places reserved for OAs) annually from five different eye hospitals. The entrance examination for the new optometry school in the NAMS has unjustified higher (40\%) weightage in ophthalmic science than that of the IOM which has only $25 \%$ weightage for the ophthalmic science. The IOM conducts entrance examinations for medicine degree along with other allied health degrees, for example, optometry and public health. The entrance questions for none of the programmes comprise more than $25 \%$ questions of their specific field. The majority of the applicants come from pure science background after completing their high schools (equivalent to A-level). The new programme, therefore, offers an unfair advantage to the OAs competing in the entrance examination. On the other hand, many applicants who may have strong academic track record but no previous exposure to ophthalmic science are at a disadvantage.

The curriculum for the new school is similar to the curriculum of the 20 years old optometry programme at IOM with the exception that the new curriculum included few new sections, for example, applied psychology, occupational optometry and laws in optometry and health management. In both curricula, therapeutics section is limited, although optometrists prescribe selective drugs under the practice guideline of the regulating body, Nepal Health Professional Council (NHPC). The NHPC is a governmental regulating body for all paramedical and allied health professionals including optometry. The Nepalese Association of Optometrists (NAO) is a professional organisation, established for striving towards excellence in the profession and also promoting the rights of Nepalese optometrists. As of January 2018, there were 118 optometrists registered with the $\mathrm{NAO}$, however the profile of optometrists working in private versus public sector and in Nepal versus overseas is not known. Until 2017, the association conducted the membership exam, which is equivalent to the licensing exam for optometrists, on behalf of the NHPC.

Anecdotal evidence suggested that Nepalese optometrists had mixed opinions regarding the new school being opened by the NAMS, particularly around the involvement of existing optometrists in the design of the programme, the curriculum, weightage of entrance examination, infrastructure for vision science laboratories and recruitment of lecturers. This survey was conducted to understand the profile of the Nepalese optometrists and to explore the perspectives of Nepalese optometrists regarding the new programme.

\section{Methods}

The prospective study respondents were contacted by email, and the survey was administered online. The online survey was developed by two authors (D.K. and H.K.) using the Google form on behalf of NAO. The survey was sent to email addresses of 118 registered NAO members between 19 January and 02 February 2018. Delivery failure notifications were obtained for 12 NAO members. After sending two reminders, 75 responses were received (two respondents were duplicated and hence excluded from the analysis). The response rate was thus $68.9 \%$ (73 out of 106). Participation in the survey was voluntary, and the respondents could withdraw from the survey at any time during the study period. The responses were kept confidential, and the data were de-identified before data analysis.

The survey included 17 semi-structured questions broadly around respondent's demographic characteristics, involvement of existing optometrists in the programme development, contents of the curriculum, weightage distribution of the entrance examination, preparation of vision science laboratories and availability of lecturers and concerns and feedback for the NAO to move forward on this regard. Fifteen questions had two to five responses with an additional 'other' option. The questionnaire also consisted of two open-ended questions to get feedback on the proposed optometry programme. Content of the survey questionnaire was derived from a closed group online discussion among NAO members and pilot tested on five members for validation. Quantitative analysis was performed using Statistical Package for Social Sciences version 23 (IBM Corporation), and qualitative analysis was performed using NVivo software, version 11 (QSR International).

For open-ended questions, thematic analysis was conducted using an inductive approach. ${ }^{78}$ The NVivo software was used for coding and organising the data. The initial codes were derived from the participants' comments based on the semantic meaning. The categories, sub-themes and themes were identified following the classification of the raw codes (Figure 1). This was an iterative process creating new themes and categories as required to capture respondents' comments in a meaningful way. 


\section{Ethical considerations}

This article followed all ethical standards for research without direct contact with human or animal subjects.

\section{Results}

\section{Demographic profile of respondents}

The mean age and standard deviation of the 73 respondents was $31.2 \pm 4.7$ years and a range from 23 to 43 years (Table 1 ). The respondents practised an average of $8.2 \pm 4.9$ years (range 1-23 years) after their professional graduation. More than half $(58.9 \%)$ of the participants were living in Nepal. Among those optometrists who were abroad, the majority were in the United States (8.2\%) followed by Australia (6.8\%). There was no association between the number of years after graduation and country of residence of the respondents ( $t$-test, $p=0.56)$.

The optometrists with a bachelor's degree were 2.29 (95\% confidence interval [CI] 0.88-5.94) times likely to remain in Nepal compared to those with a master's or higher qualification $(p=0.08)$. The highest degree of qualification was not significantly different between the optometrists graduated from IOM and those from other institutes outside of Nepal $\left(\chi^{2}=6.60, p=0.08\right)$. Institute of Medicine graduates were 0.35 (95\% CI $0.12-0.98)$ times likely to remain in Nepal compared to those graduated from other institutes $(p=0.04)$.
TABLE 1: Demographics of survey respondents.

\begin{tabular}{|c|c|c|c|}
\hline Characteristics & Mean ( \pm s.d.) & Number & $\%$ \\
\hline Age (years) & $31.2 \pm 4.7$ & - & - \\
\hline Range & - & 23 to 43 & - \\
\hline \multicolumn{4}{|l|}{ Sex } \\
\hline Male & - & 57 & 78.1 \\
\hline Female & - & 15 & 20.5 \\
\hline Other & - & 1 & 1.4 \\
\hline \multicolumn{4}{|l|}{ Current residence } \\
\hline Nepal & - & 43 & 58.9 \\
\hline Outside Nepal & - & 30 & 41.1 \\
\hline \multicolumn{4}{|l|}{ Graduating institute } \\
\hline Institute of Medicine & - & 46 & 63.0 \\
\hline Other & - & 27 & 37.0 \\
\hline \multicolumn{4}{|l|}{ Qualification } \\
\hline Bachelor of Optometry & - & 38 & 51.4 \\
\hline Doctor of Optometry & - & 6 & 8.3 \\
\hline Master's degree & - & 21 & 29.2 \\
\hline Doctor of Philosophy (PhD) & - & 8 & 11.1 \\
\hline \multicolumn{4}{|l|}{ Current position $(n=70)$} \\
\hline Clinician & - & 32 & 44.4 \\
\hline Clinician and lecturer & - & 16 & 22.2 \\
\hline Post-doctoral position & - & 5 & 6.9 \\
\hline Student (Master's /PhD) & - & 17 & 23.6 \\
\hline \multicolumn{4}{|l|}{ Clinical practice location $(n=48)$} \\
\hline Eye hospital optometrist & - & 21 & 44.8 \\
\hline Private practice optometrist & - & 9 & 18.4 \\
\hline Teaching hospital optometrist & - & 9 & 18.4 \\
\hline Practice optometry overseas & - & 9 & 18.4 \\
\hline
\end{tabular}

s.d., standard deviation.

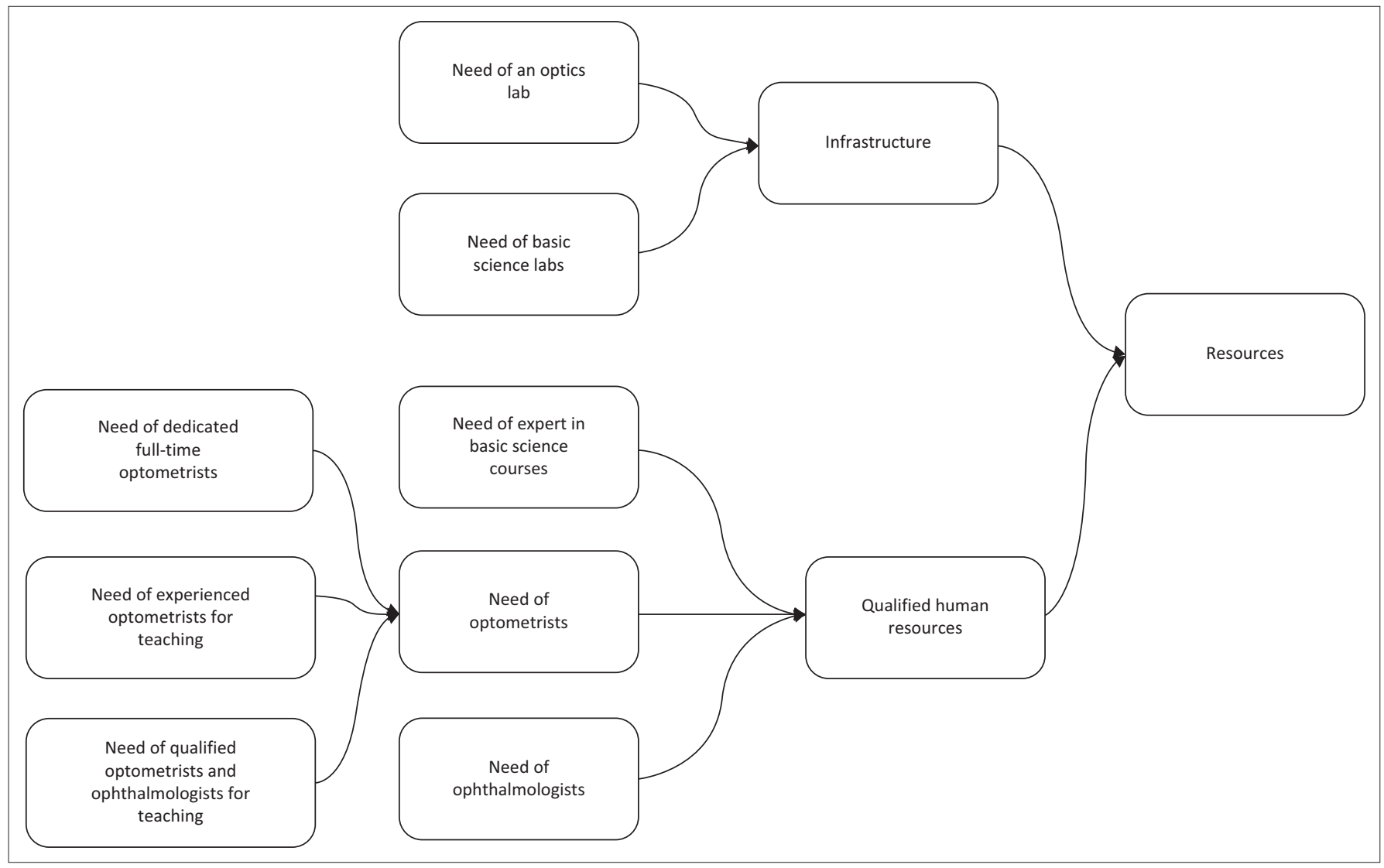

FIGURE 1: An example showing a coding structure demonstrating how the themes, sub-themes and categories were generated from the raw codes. 
Nearly a half (44.4\%) of the respondents practised as clinicians, while $22.2 \%$ worked as clinicians as well as lecturers. Out of those who worked as clinicians, $44.8 \%$ worked in eye hospitals, equal number of respondents $(18.4 \%)$ worked in teaching hospitals, private practice and abroad.

\section{Involvement of the Nepalese Association of Optometrists/optometrists}

More than half $(61.8 \%)$ of the respondents thought that involvement of the NAO or optometrists in the design of the new optometry school was inadequate. A vast majority (93.2\%) of the respondents expressed the view that NAO or optometrists should have been involved more in the development of the programme (Table 2).

\section{Optometry curriculum and entrance examination}

More than half (57.5\%) of the respondents suggested that the new optometry programme should go ahead with a revised curriculum and well-equipped laboratories (Table 2). Over half $(53.1 \%)$ of the respondents found that the curriculum was not adequate, particularly in basic sciences, pharmacology and other specialised optometry areas such as paediatric optometry and ophthalmic optics.

More than three-quarters of the respondents (75.3\%) found that the $40 \%$ weightage of ophthalmic science in the entrance examination would be favourable to OAs. Among those who thought the entrance examination would be favourable to OAs, nearly two-thirds $(66 \%)$ of the respondents were IOM graduates, while the remaining one-third (34\%) were graduates from other institutes. This difference was statistically significant $\left(\chi^{2}=9.15, p=0.02\right)$

\section{Infrastructure and lecturers}

Over two-thirds $(70.0 \%)$ of the respondents thought there was inadequate infrastructure (vision science laboratories) for teaching in the five eye hospitals. More than half (54.2\%) of the respondents thought that teaching students in five different hospitals was likely to lead to inconsistent competencies among graduates. On the other hand, $40.3 \%$ of the respondents thought the competency among the graduates would be consistent if lecturers undergo a standard training programme. Nearly half $(45.2 \%)$ of the respondents had an opinion that there should be at least five to seven fulltime lecturers to teach 40 students per year. The responses on the required number of lecturers for the new programme were not associated with the qualification of the respondents $\left(\chi^{2}=8.52, p=0.48\right)$.

\section{Concerns and feedback}

Thematic analysis resulted into four broad themes: (1) quality assurance and control; (2) resources; (3) curriculum development and implementation; and (4) professional standard and opportunities, which consisted of a total of 174 comments.
TABLE 2: Summary of the optometry survey findings.

\begin{tabular}{|c|c|c|}
\hline Questions & Number & $(\%)$ \\
\hline \multicolumn{3}{|l|}{ Involvement of optometrists } \\
\hline \multicolumn{3}{|c|}{$\begin{array}{l}\text { How was the involvement of optometrists before opening the new programme? } \\
(n=68)\end{array}$} \\
\hline Adequate & 23 & 33.8 \\
\hline Inadequate & 42 & 61.8 \\
\hline Does not matter & 3 & 4.4 \\
\hline \multicolumn{3}{|c|}{$\begin{array}{l}\text { Should NAMS have involved optometrists more before opening the new school? } \\
(n=73)\end{array}$} \\
\hline Yes & 68 & 93.2 \\
\hline No & 3 & 4.1 \\
\hline Does not matter & 2 & 2.7 \\
\hline \multicolumn{3}{|c|}{ Optometry curriculum and entrance examination } \\
\hline \multicolumn{3}{|c|}{ Should the proposed new programme go ahead in its current form? $(n=68)$} \\
\hline Yes & 12 & 16.4 \\
\hline No & 14 & 19.2 \\
\hline $\begin{array}{l}\text { Should go ahead with revised } \\
\text { curriculum and equipped laboratories }\end{array}$ & 42 & 57.5 \\
\hline \multicolumn{3}{|c|}{ How is the proposed new curriculum? $(n=64)$} \\
\hline Adequate & 18 & 28.1 \\
\hline Inadequate & 34 & 53.1 \\
\hline Not familiar with the curriculum & 12 & 18.8 \\
\hline \multicolumn{3}{|c|}{$\begin{array}{l}\text { How do you find } 40 \% \text { ophthalmic science weightage in entrance examination? } \\
(n=73)\end{array}$} \\
\hline Appropriate & 7 & 9.6 \\
\hline Favourable for OAs & 55 & 75.3 \\
\hline Cannot decide & 11 & 15.1 \\
\hline \multicolumn{3}{|l|}{ Infrastructure and lecturers } \\
\hline \multicolumn{3}{|c|}{$\begin{array}{l}\text { Are there adequate infrastructure and lecturers for the new programme? } \\
(n=70)\end{array}$} \\
\hline Yes & 7 & 10.0 \\
\hline No & 49 & 70.0 \\
\hline Cannot decide & 14 & 20.0 \\
\hline \multicolumn{3}{|c|}{ How do you feel about teaching students at five eye hospitals? $(n=72)$} \\
\hline Perfectly fine & 4 & 5.5 \\
\hline $\begin{array}{l}\text { Likely to lead inconsistent competency } \\
\text { among graduates }\end{array}$ & 39 & 54.2 \\
\hline $\begin{array}{l}\text { It is fine provided the lecturers go } \\
\text { through standard training programme }\end{array}$ & 29 & 40.3 \\
\hline \multicolumn{3}{|c|}{$\begin{array}{l}\text { How many full-time lecturers will be required to teach } 40 \text { students per year? } \\
(n=73)\end{array}$} \\
\hline $1-4$ & 5 & 6.8 \\
\hline $5-7$ & 33 & 45.2 \\
\hline $8-10$ & 25 & 34.2 \\
\hline$>10$ & 10 & 13.7 \\
\hline
\end{tabular}

NAMS, National Academy of Medical Science; OAs, ophthalmic assistants.

\section{Quality assurance and control}

About two-thirds of the responders expressed concerns about quality assurance and control mechanisms in the new optometry programme. Several of them said that no or minimal participation of the optometrists or the NAO in designing the programme was of great concern:

'How can people of other professions plan to establish a degree programme in Optometry without even consulting optometrists?' (Participant ID19, male, teaching hospital optometrist)

Many of them were concerned about the way the entrance examination was planned. Many participants said that it should be a free competition, not biased to a particular group, to ensure quality. A few of them said that there should be fewer or no questions from ophthalmic science in the entrance examination as even the prospective students with excellent high school grades may struggle to do well in this area. Some 
participants reported that having students with science background is important in optometry. Expecting threats to the quality of the optometrists produced from the new programme, a few participants indicated a need for strict examinations from the NAO or the NHPC to control quality.

\section{Resources}

Nearly half of the respondents expressed concerns regarding the resources available for running the optometry programme. The participants reported the need for a team of qualified and experienced optometrists, ophthalmologists and basic science experts to provide quality education. Similarly, they reported concerns about not having enough infrastructure to run a new optometry programme. They highlighted the need to establish basic science and optical laboratories before starting the programme.

\section{Curriculum development and implementation}

Nearly half of the respondents urged for an updated curriculum and for the appropriate implementation of the curriculum. Many of them recommended extended basic science courses in terms of the content and duration of teaching. Some participants voiced the need to add content such as community eye health, pharmacology, ophthalmic optics and paediatric optometry. For maintaining quality and consistency in teaching, many suggested teaching in a single eye hospital, rather than in five eye hospitals, prior to sending the students for clinical placements:

'I had a bad experience in my clinical placement. My clinical supervisor didn't care about my learning; just used me as a manpower. I strongly believe that teaching all students in the academy and sending them to hospitals only for placement the best idea.' (Participant ID71, male, private practitioner)

\section{Professional standard and opportunities}

About half of the respondents raised concerns about professional standards and opportunities introduced with the design of new programme. Many urged that it is a high time optometrists lobby for established scope of practice of all eye care professionals in the country. Similarly, many participants said that it is important for the government to recognise the optometry profession before starting another programme. Some of them expressed concerns that government has no or limited employment opportunities for optometrists. They were worried that the situation might get worse with a high number of optometrists graduating each year, while others were not concerned about the number of students being graduated, but rather were concerned about the quality and respect of the optometry graduates:

'We should not hesitate of the numbers of optometrist production rather we should force for their respected position and job description.' (Participant ID69, male, eye hospital optometrist)

Respondents' viewpoints were divided about the roles of other eye care professionals in the growth of the optometry profession. Few of them also raised issues such as professional rivalry. The participants expressed several strategies to address these concerns. The feedback ranged from communicating with stakeholders and conducting advocacy programmes, to filing a case in court. Most of them favoured for negotiations and communication:

'NAO should discuss the issues with eye care leaders, particularly to the NNJS leaders. Discussion and negotiation with the association of the ophthalmic assistants, the national health professional council, and other relevant authorities may result into a solution which can be win-win for all eye care professionals working towards a common goal of delivering quality eye care services. This will also ensure healthy relationship between the professions.' (Participant ID10, male, clinician and lecturer)

'Filing a case in court will compel everyone to come in a table and talk and the issue will be everywhere in the media and thus among the public.' (Participant ID18, male, studying PhD)

Nevertheless, respondents also reported positive comments about the programme. Some said that the new school might bring several opportunities to the optometrists. Having a greater number of optometrists will increase the chances of having an independent regulatory body (optometry council) to strive for the benefit of the profession of optometry:

'Given the situation where several Nepalese students travel to India to study Optometry, it is a good step to start Optometry programme in the country.' (Participant ID3, male, graduated overseas)

\section{Discussion}

The results of the survey provide a profile of Nepalese optometrists and explore their perspectives regarding the expansion of the profession in the country. Nepal needs the initiation of the long-awaited second optometry school; however, the existing optometrists were concerned about the preparation of the new school, particularly around vision science laboratories and lecturers.

Forty-one per cent of optometry graduates were working in foreign countries after graduation. This figure is comparable to medical graduates of the IOM: $36 \%$ of them worked overseas after completing their degree ${ }^{9}$ but it is much higher compared to emigration rates within eye health professionals, ophthalmologists (11\%) and OAs (27.4\%). ${ }^{10}$ This study found that optometrists graduated from IOM were 0.35 times more likely to remain in Nepal than those graduating elsewhere. The higher rates of emigration among IOM graduates are possibly because of two reasons: firstly, optometrists still lack job securities, career development and further study opportunities in the country, and secondly, the quality of IOM graduates is competitive enough to emigrate. ${ }^{11} \mathrm{~A}$ recent study conducted in Saudi Arabia showed that optometrists can manage about two-thirds of eye condition in patients presenting in the primary health care centre. ${ }^{12}$ Although data on this regard are not available for Nepal, we believe that a similar proportion of patients can be treated by optometrists at regional eye hospitals. Therefore, there is a need to recognise optometrists as primary eye care providers in the country. 
It is important to note that there is no standard benchmark for the establishment of an undergraduate programme in optometry, while in psychology there are eight domains: curriculum, assessment issues, student learning outcomes, programme resources, student development, faculty characteristics, programme climate, and administrative support. ${ }^{13}$ This makes it difficult to maintain the standard of optometry programmes uniform within the country and across the countries. The Brien Holden Vision Institute, which has provided support to open more than 10 new optometry schools around the world, particularly in Africa, Asia and Latin America and the Caribbean, has developed a curriculum for the optometry programme, ${ }^{14}$ but there is no uniformity in the curriculum across optometry schools in different countries. For example, Bachelor of Science (Optometry) curriculum in the Mzuzu University in Malawi is not the same as that of Bachelor of Science (Optometry and Vision Sciences) in the Masinde Muliro University of Science and Technology in Kenya. In addition, the regulation of the standard of a profession is usually maintained by a governmental council body. However, in case of optometry, which is a new profession in many countries, own Optometry Council body does not exist, and the optometry profession is under the General Health Council where the representation of the optometrists in the executive body is often not adequate to make substantial contribution towards regulation of the profession.

More than two-thirds of the respondents in this study had an opinion that $40 \%$ weightage of ophthalmic science in the entrance examination would be biased towards the OAs as the science stream students would not have studied much of ophthalmic science. It is generally accepted that the institutional admission policy is often a reflection of their quality ranking. ${ }^{15}$ For example, in a review of the psychology programmes of over 100 institutions in North America, the higher score in entrance examinations positively correlated with the higher academic performance and the higher completion rate. ${ }^{16}$ Therefore, the entrance exam should not be compromised to maintain the quality of the graduates. There was a significant difference between the IOM $(66 \%)$ and other graduates $(34 \%)$ who had an opinion that $40 \%$ weightage on ophthalmic science would be favourable to the OAs. It is important to note that most of the OAs who study optometry wanted to upgrade their qualification which otherwise would not be possible in Nepal. It is argued that if there were more questions from ophthalmic science, it would be easier for the OAs to enrol in optometry. While upgrading the existing cadres is commendable, there should be a balance between creating opportunities for high school graduates and the OAs.

More than two-thirds of the respondents thought that the NAMS did not have adequate infrastructure, particularly for vision science and optical laboratories to start the programme. It is argued that learning by doing practicals in the labs would increase the success rate of students as it is seen in other programmes like psychology. ${ }^{16,17}$ Similarly, emphasis should be given on full-time staffing, strategies for achieving consistency in topic studies, readings and assignments to improve the quality of the optometry training.
North American studies have found that adequate staffing is important to motivate students in learning activities. ${ }^{16,18}$ This is going to be a major challenge in Nepal as qualified faculty need to be recruited and trained. Anecdotal evidence suggested that there was a lack of proper planning of teaching in new optometry schools. For example, the ad hoc recruited lecturers were not paid several months after delivering the lectures as the school management did not have any plan on the rates that the lecturers would be paid. Furthermore, decentralisation of the programme is going to increase this burden, and this will impact on both recruitment and subsequent quality of the programme. Hence, the suggestion by optometrists that maintaining the quality and consistency through centralised teaching, rather than teaching in the individual hospitals, prior to sending the students for clinical placements makes sense.

Starting a new optometry school can be considered as a part of the health system. Human resources (health workforce), which is one of the six building blocks (service delivery, health work force, information systems, medical products, vaccines and technologies, financing and governance) of the health systems framework, play an important role to achieve a wellfunctioning health system. ${ }^{19}$ A review of more than 100 studies from low- and middle-income countries found that nearly half of the studies considered health system impact on one building block, particularly service delivery. ${ }^{20}$ It is important to consider other building blocks of the health system such as health workforce (personnel management, training in preservice and in-service) and governance (level of decisionmaking, consumer and stakeholder involvement) so that health care quality is optimum and sustainable. ${ }^{19}$ Inadequate involvement of existing optometrists from both clinical and academic fields except in 1-day curriculum development workshop as one of the stakeholders showed that the new optometry programme certainly did not pay adequate attention to all six building blocks of the health system.

This study has some strengths: firstly, quantitative data analysis and qualitative data analysis were performed to explore the opinions of the existing optometrists towards the new programme. While demographic, educational and employment profile of the respondents were analysed with quantitative methods, concerns of the optometrists towards the new programme were analysed using thematic analysis. Thematic analysis is a core method of qualitative data analysis, which is useful for many forms of qualitative studies. ${ }^{21}$ Secondly, the response rate of the survey was $69 \%$, which can be considered as high for online surveys. The response rates among Ghanaian optometrists regarding optometry practice was $62 \%,{ }^{22}$ and it was $60 \%$ for the medical graduates of the IOM in a career practice location survey. ${ }^{9}$ Generally, online surveys have lower response rates than paper-based surveys. ${ }^{23}$ For example, a meta-analysis of 68 online surveys found a mean response rate of $40 \%$, while the lowest response rate was only $20 \%{ }^{23}$

This study has some limitations: firstly, although more than 350 optometrists are registered with the NHPC (SKM, President of Nepalese Association of Optometrists 2018, personal communication, February 26), which is a regulating body for 
optometrists along with other allied health professions, only about 118 optometrists were registered with the NAO. The sample size would have been larger if we had sent the survey to the NHPC registered members; however, because of the unavailability of the email addresses, this could not be done. Secondly, as the respondents were only optometrists, the views of the NAMS and five involved eye hospitals were not included in the study. It would have been better if the findings of the survey were triangulated with the opinions of all stakeholders: NAMS, involved eye hospitals and NHPC representatives. Future studies should be conducted involving all the stakeholders to confirm the study findings.

In this study, we have compared our findings with other health professions regarding the standards, entrance criteria and response rate as there was only a limited published literature on the optometry profession. Nevertheless, we believe that this study presents issues that may need attention while starting a new optometry programme in other low- and middle-income countries. As optometry is relatively a new profession in many countries, this article may be a reference document to the non governmental organisations and policymakers working in the optometry education sector.

In conclusion, the introduction of a second optometry school is necessary in Nepal which will assist to reduce the optometrist to population ratio; however, claims of poor planning and implementation created a concern among existing optometrists. The major areas for improvement of the new school are an impartial entrance examination, well-equipped laboratories and recruiting of full-time lecturers as well as maintaining the uniformity of training across different hospitals through a standard teaching method. Nevertheless, it is still not too late to address those issues while the programme is progressing.

Recently, the Master of Optometry programme is offered by two institutions affiliated to the Pokhara University: Himalayan Eye Hospital and Tilgana Institute of Ophthalmology with an intake of 12 students per year. Establishment of new optometry schools shows realisation of the need of expansion of optometry training in Nepal. The findings of this study highlight the importance of correct steps and need for involving key stakeholders in expanding the programme to ensure quality of the profession in the future.

\section{Acknowledgements}

The authors thank Dr Safal Khanal, University of Auckland, for his help while developing the survey questionnaire. They also thank Mr Sanjeeb Mishra, President, Nepalese Association of Optometrists, for sending the survey to all registered members. They would also like to thank all optometrists who participated in the survey.

\section{Competing interests}

The authors have declared that no competing interests exist.

\section{Authors' contributions}

D.K. was responsible for project design, data collection and writing the draft of the article. D.K. and H.K. were responsible for data analysis. D.K., H.K., P.P. and K.N. revised all versions of the article.

\section{Funding information}

This research received no specific grant from any funding agency in the public, commercial or not-for-profit sectors.

\section{Data availability statement}

The survey questionnaire is available from the first author on request.

\section{Disclaimer}

The views and opinions expressed in this article are those of the authors and do not necessarily reflect the official policy or position of any affiliated agency of the authors.

\section{References}

1. Thulasiraj RD, Sundaram RM. Optical services through outreach in South India: A case study from Aravind Eye Hospitals. Community Eye Health. 2006;19(58):29-30.

2. Central Bureau of Statistics, Government of Nepal. National Population and Housing Census 2011: Population projection 2011-2031. [homepage on the Internet]. Kathmandu; 2014. [cited 2018 May 25]. Available from: https://unstats.un.org/ unsd/demographic-social/census/documents/Nepal/Nepal-Census-2011-Vol1.pdf.

3. Mahat B, Kaphle D, Kandel H. Clear vision. The Kathmandu Post [homepage on the Internet]. 2018 March 25. [cited 2018 Sep 10]. Available from: http:// kathmandupost.ekantipur.com/news/2018-03-25/clearvision.html?fbclid=IWAR1 z3gXMlbCUqAmUZk63T-wSvY6Pzmn-hmVnEF77-sz3KYMrHIt8QjMLoxY.

4. Marasini S, Kaphle D. Retain optometrists. My Republica [homepage on the Internet]. 2018 January 14 [cited 2018 Aug 10]. Available from: http://www. myrepublica.com/news/34328/?categoryld=81.

5. Kandel H, Murthy GVS, Bascaran C. Human resources for refraction services in Central Nepal. Clin Exp Optom. 2015;98(4):335-341. https://doi.org/10.1111/ cxo.12286

6. World Health Organization. The impact of myopia and high myopia [homepage on the Internet]. Geneva; 2017 [cited 2018 Mar 11]. Available from: http://www. who.int/blindness/causes/MyopiaReportforWeb.pdf.

7. Ryan GW, Bernard HR. Techniques to identify themes. Field Methods. 2003;15(1): 85-109. https://doi.org/10.1177/1525822X02239569

8. Fereday J, Muir-Cochrane E. Demonstrating rigor using thematic analysis: A hybrid approach of inductive and deductive coding and theme development. Int J Qual Methods. 2006;5(1):80-92. https://doi.org/10.1177/160940690600500107

9. Zimmerman M, Shakya R, Pokhrel BM, et al. Medical students' characteristics as predictors of career practice location: Retrospective cohort study tracking graduates of Nepal's first medical college. BMJ. 2012;345:e4826. https://doi org/10.1136/bmj.e4826

10. Apex Body for Eye Health. Mid-term review of VISION 2020: The Right to Sight. Kathmandu, Nepal: Ministry of Health and Population; 2012.

11. Kaphle D, Marasini S. Seeing clearly. Kathmandu Post [homepage on the Internet]. 2018 March 6. [cited 2018 Sep 18]. Available from: http://kathmandupost. ekantipur.com/news/2018-03-06/seeing-clearly.html.

12. Aldebasi $\mathrm{YH}$, Ahmed $\mathrm{MI}$, Monaco WA. Are optometrists necessary in primary health care centres in Saudi Arabia? Afr Vision Eye Health. 2018;77(1):a402 https://doi.org/10.4102/aveh.v77i1.402

13. Dunn DS, McCarthy MA, Baker S, Halonen JS, Hill GW. Quality benchmarks in undergraduate psychology programs. Am Psychol. 2007:62(7):650-670. https:// doi.org/10.1037/0003-066X.62.7.650

14. Brien Holden Vision Institute. Where we work [homepage on the Internet]. New South Wales; 2018 [cited 2018 Apr 15]. Available from: https://www. brienholdenvision.org/public-health/where-we-work.html.

15. Richards A, Coddington R. 30 ways to rate a college [homepage on the Internet]. 2010 [updated 2010 Aug 29] [cited 2018 Aug 18]. Available from: https://www. chronicle.com/article/30-Ways-to-Rate-a-College/124160.

16. Stoloff ML, Curtis NA, Rodgers M, Brewster J, McCarthy MA. Characteristics of successful undergraduate psychology programs. Los Angeles, CA: Sage, 2012; p. 91-99.

17. Dolinsky B, Kelley JM. For better or for worse: Using an objective program assessment measure to enhance an undergraduate psychology program. Teach Psychol. 2010;37(4):252-256. https://doi.org/10.1080/00986283.2010.510978

18. National Survey of Student Engagement. Major differences: Examining student engagement by fields of study [homepage on the Internet]. Bloomington; 2010 [cited 2018 Sep 10]. Available from: http://nsse.indiana.edu/NSSE_2010_Results/ pdf/NSSE_2010_AnnualResults.pdf. 
19. World Health Organization. Everybody's business: Strengthening health systems to improve health outcomes [homepage on the Internet]. Geneva; 2007 [cited
2018 Mar 30]. Available from: https://www.who.int/healthsystems/strategy/ 2018 Mar 30]. Available
everybodys business.pdf.

20. Adam T, Hsu J, De Savigny D, Lavis JN, Røttingen JA, Bennett S. Evaluating health systems strengthening interventions in low-income and middle-income countries: Are we asking the right questions? Health Policy Plan. 2012;27(Suppl 4):iv9-iv19. https://doi.org/10.1093/heapol/czs086
21. Braun V, Clarke V. Using thematic analysis in psychology. Qual Res Psychol. 2006;3(2):77-101. https://doi.org/10.1191/1478088706qp063oa

22. Boadi-Kusi SB, Ntodie M, Mashige KP, Owusu-Ansah A, Antwi Osei K. A cross-sectional Ghana. Clin Exp Optom. 2015;98(5):473-477. https://doi.org/10.1111/cxo.12291

23. Nulty DD. The adequacy of response rates to online and paper surveys: What can be done? Assess Eval High Educ. 2008;33(3):301-314. https://doi.org/10.1080/ 